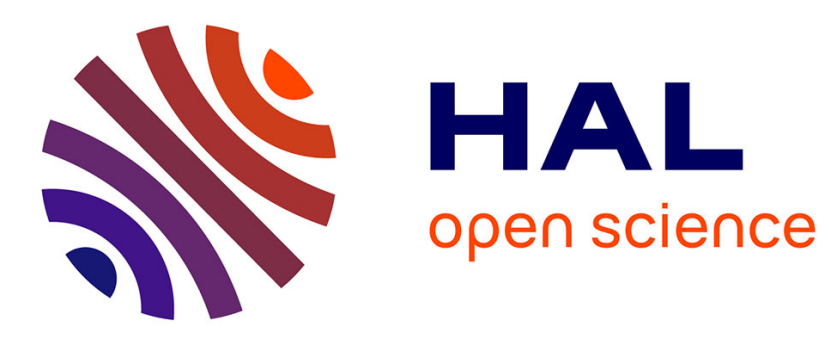

\title{
Immunoglobulin-binding domains: Protein L from Peptostreptococcus magnus
}

\author{
Nicholas G Housden, Steven Harrison, Hazel R Housden, Karen-Anne \\ Thomas, Jennifer A Beckingham, Siân E Roberts, Stephen P Bottomley, Marc \\ Graille, Enrico Stura, Michael G Gore
}

\section{To cite this version:}

Nicholas G Housden, Steven Harrison, Hazel R Housden, Karen-Anne Thomas, Jennifer A Beckingham, et al.. Immunoglobulin-binding domains: Protein L from Peptostreptococcus magnus. Journal of Biological Chemistry, 2003, 279 (10), pp.9370 - 9378. 10.1074/jbc.m312938200 . hal-03299363

\section{HAL Id: hal-03299363 https://hal.science/hal-03299363}

Submitted on 26 Jul 2021

HAL is a multi-disciplinary open access archive for the deposit and dissemination of scientific research documents, whether they are published or not. The documents may come from teaching and research institutions in France or abroad, or from public or private research centers.
L'archive ouverte pluridisciplinaire HAL, est destinée au dépôt et à la diffusion de documents scientifiques de niveau recherche, publiés ou non, émanant des établissements d'enseignement et de recherche français ou étrangers, des laboratoires publics ou privés. 


\title{
Observation and Characterization of the Interaction between a Single Immunoglobulin Binding Domain of Protein $L$ and Two Equivalents of Human $\kappa$ Light Chains*
}

Received for publication, November 26, 2003 Published, JBC Papers in Press, December 10, 2003, DOI 10.1074/jbc.M312938200

\author{
Nicholas G. Housden $\ddagger$, Steven Harrison $\ddagger \S$, Hazel R. Housden $\ddagger$, Karen-Anne Thomas $\ddagger$, \\ Jennifer A. Beckinghamł, Siân E. Robertsł, Stephen P. Bottomleył, Marc Grailleף, \\ Enrico Sturaף, and Michael G. Gore俨 \\ From the $\ddagger$ Division of Biochemistry and Molecular Biology, School of Biological Sciences, University of Southampton, \\ Bassett Crescent East, Southampton, Hants SO16 7PX, United Kingdom and the ПCEA, Département d'Ingénierie et \\ d'Etudes des Protéines, (DIEP), C.E. Saclay, 91191 Gif-sur-Yvette Cedex, France
}

\begin{abstract}
Detailed stopped-flow studies in combination with site-directed mutagenesis, isothermal titration calorimetry data and x-ray crystallographic knowledge have revealed that the biphasic pre-equilibrium fluorescence changes reported for a single Ig-binding domain of protein $\mathrm{L}$ from Peptostreptococcus magnus binding to $\kappa$ light chain are due to the binding of the $\kappa$ light chain at two separate sites on the protein $L$ molecule. Elimination of binding site 2 through the mutation A66W has allowed the $K_{d}$ for $\kappa$ light chain binding at site 1 to be measured by stopped-flow fluorescence and isothermal titration calorimetry techniques, giving values of $48.0 \pm$ 8.0 nM and 37.5 $\pm 7.3 \mathrm{~nm}$ respectively. Conversely, a double mutation Y53F/L57H eliminates binding at site 1 and has allowed the $K_{d}$ for binding at site 2 to be determined. Stopped-flow fluorimetry suggests this to be $3.4 \pm 0.8 \mu \mathrm{M}$ in good agreement with the value of $4.6 \pm 0.8 \mu \mathrm{M}$ determined by isothermal titration calorimetry. The mutation Y53F reduces the affinity of site 1 to approximately that of site 2.
\end{abstract}

Protein $\mathrm{L}$ is a multidomain cell wall bound protein found in $\sim 10 \%$ of the Peptostreptococcal isolates (1) and contains a series of repeated domains, some of which are able to bind to immunoglobulins without initiating an immune response. Expression of this protein has been correlated to the virulence of these opportunistic pathogenic bacteria (1) that are found in the gastrointestinal and urogenital tracts (2). Its presence has been found to cause cellular responses such as histamine release from basophils and mast cells (3) presumably by crosslinking IgE molecules bound to surface Ig receptors.

${ }^{1} \mathrm{H}$ NMR spectroscopy of a single Ig-binding domain of protein $\mathrm{L}$ (isolated from strain $\left.312, \mathrm{PpL}_{312}\right)^{1}$ revealed that $\mathrm{PpL}_{312}$

* This work was supported by the Wellcome Trust and Biotechnology and Biological Sciences Research Council Grants 055640/Z/98/Z/ST/RC, E10136, E15767, and E11896 (to M. G. G.). The costs of publication of this article were defrayed in part by the payment of page charges. This article must therefore be hereby marked "advertisement" in accordance with 18 U.S.C. Section 1734 solely to indicate this fact.

$\S$ These authors received a Biotechnology and Biological Sciences Research Council studentship.

$\|$ To whom correspondence should be addressed: Dept. of Biochemistry, School of Biological Sciences, University of Southampton, Bassett Crescent East, Southampton, Hants SO16 7PX, UK. Tel.: 44-2380594313; Fax: 44-23-80594459; E-mail: M.G.Gore@soton.ac.uk.

${ }^{1}$ The abbreviations used are: $\mathrm{PpL}_{312}$, single Ig-binding domain of protein $\mathrm{L}$ from strain 312 of $P$. magnus; $\mathrm{PpL}_{3316}$, single Ig-binding domain of protein L from strain 3316 of $P$. magnus; $\kappa$-chain, $\kappa$ light chain; wt, wild-type; FRET, fluorescence resonance energy transfer. is a rigid structure consisting of a $\beta$-sheet, formed by two pairs of antiparallel $\beta$-strands, lying on top of a single $\alpha$-helical section (4), with a flexible $\mathrm{N}$ terminus (5). Further NMR studies (6) led to the proposal that the binding site of $\mathrm{PpL}_{312}$ for $\kappa$-chain involves residues from the second $\beta$-strand and from the loop between the third $\beta$-strand and the $\alpha$-helix and located the binding site for $\mathrm{PpL}_{312}$ on the $\kappa$-chain to the second $\beta$-strand and the two $\beta$-strands located on the outer surface of the framework region of the $\mathrm{V}_{\mathrm{L}}$ domain (7).

Parallel studies on the binding interaction of a single Igbinding domain of protein $\mathrm{L}$ from strain $3316\left(\mathrm{PpL}_{3316}\right)$ found that it forms a high affinity complex with $\kappa$-chains with a $K_{d}$ of $112 \mathrm{~nm}(8,9)$. The x-ray crystallographic structure of this domain has been determined in complex with the human antibody fragment, Fab 2A2, and revealed that two Fab $2 \mathrm{~A} 2$ fragments can in fact bind to sites on opposite faces of $\mathrm{PpL}_{3316}$ (10). Site 1 of $\mathrm{PpL}_{3316}$ is that characterized by Beckingham et al. (9) and equivalent to the site studied on $\mathrm{PpL}_{312}$ using NMR by Wikström et al. (5). Site 2 of $\mathrm{PpL}_{3316}$, involving part of the helix and strands 3 and 4 , was identified for the first time by the crystallographic study (10). This site has not yet been characterized although preliminary studies suggested that the affinity of site 2 is lower than that of site 1 (10).

By use of a program of site directed mutagenesis we have been able to derive the relative binding affinities of sites 1 and 2 and propose a mechanism by which $\mathrm{PpL}_{3316}$ binds $\kappa$ light chains that is consistent with published data. The hydroxyl group of $\mathrm{Tyr}^{53}$ is important for the formation of a high affinity complex at site 1. Previous enzyme-linked immunosorbent assay experiments (11) have shown that nitration of $\mathrm{Tyr}^{53}$ or its mutation to Phe dramatically increases the $K_{d}$ of the $\kappa$-chain$\mathrm{PpL}_{3316}$ interaction. Another important residue at site 1 is $\mathrm{Leu}^{57}$. No binding of the $\kappa_{1}$-chain used in these studies can be detected at site 1 of the mutant Y53F/L57H by fluorimetry or isothermal titration calorimetry, and this mutant is thus ideal for measuring the affinity at site 2 .

Important residues for binding at site 2 are $\mathrm{Asp}^{55}$ and $\mathrm{Ala}^{66}$. The mutation D55A eliminates a salt bridge and dramatically weakens or eliminates binding (12), and conversely, the mutation $\mathrm{A} 66 \mathrm{~W}$ is predicted to cause a steric clash removing binding at site 2 . This is born out by fluorimetry experiments reported here and therefore the $\mathrm{A} 66 \mathrm{~W} \mathrm{PpL}_{3316}$ is suitable for determining the affinity of site 1 .

The fluorescence properties of tryptophan residues are highly sensitive to their immediate environment (13), and changes in the fluorescence emission from Trp residues have been used to study protein folding and unfolding events, pro- 
tein conformational changes, and to monitor binding interactions between proteins and various ligands (14). We have therefore introduced unique Trp residues into $\mathrm{PpL}_{3316}$ to monitor the binding reaction with $\kappa$-chain. Previous fluorescence studies have used F39W $\mathrm{PpL}_{3316}$ to report the binding interaction between $\kappa$-chain and $\mathrm{PpL}_{3316}$. However, upon introduction of secondary mutations into the F39W $\mathrm{PpL}_{3316}$ construct, expression levels and stability of the protein are compromised. Therefore the I34W $\mathrm{PpL}_{3316}$ mutant, which has a Trp residue located toward the $\mathrm{N}$ terminus of $\beta$-strand 2 , has been selected to study binding at the site 1 interface (see Fig. 1a); this construct is tolerant to the introduction of further mutations. The mutant Y64W $\mathrm{PpL}_{3316}$ (Trp residue on $\beta$-strand 3 and close to residues $\mathrm{Thr}^{65}, \mathrm{Ala}^{66}, \mathrm{Asp}^{67}$, and $\mathrm{Leu}^{68}$, all of which are involved in site 2 contacts (10)) was made to monitor binding at site 2 (see Fig. 1b).

\section{EXPERIMENTAL PROCEDURES}

Phosphate buffers and other reagents were all of analytical grade and purchased from BDH. The human IgG and $\kappa_{1}$-chain for fluorescence experiments were generous gifts from Professor Martin Glennie, Southampton General Hospital, UK.

Mutagenesis-The mutated $\mathrm{PpL}_{3316}$ constructs, I34W, Y64W, and Y64W/Y53F, were produced through the Kunkel method (15) of sitedirected mutagenesis. The I34W/Y53F, I34W/Y53F/L57H, Y64W/Y53F/ $\mathrm{L} 57 \mathrm{H}, \mathrm{A} 66 \mathrm{~W}$, and I34W/A66W $\mathrm{PpL}_{3316}$ mutant proteins were made through two-sided splicing by overlap extension PCR mutagenesis (16). The presence of each mutation was confirmed by DNA sequencing and the mutant proteins were prepared in the same manner as the wildtype (wt) protein (8).

Fluorescence Measurements-Fluorescence emission spectral measurements were made on a Hitachi F-2000 fluorimeter, with the temperature of the cell being maintained at $15{ }^{\circ} \mathrm{C}$ by circulating water. All solutions were prepared in filtered $20 \mathrm{~mm}$ potassium phosphate buffer, $\mathrm{pH}$ 8.0. Scans of the emission spectra were made using excitation and emission band passes of $5 \mathrm{~nm}$. Emission spectra were measured using excitation wavelengths of 280 and $295 \mathrm{~nm}$, with a scan rate of 60 $\mathrm{nm} / \mathrm{min}$.

Stopped-flow Fluorescence Measurements-An Applied Photophysics SX.17MV stopped-flow spectrophotometer fitted with a 2-ml syringe was used to study pre-equilibrium fluorescence changes upon mixing of $\mathrm{PpL}_{3316}$ with $\kappa$-chain. The temperature was maintained at $15^{\circ} \mathrm{C}$ (unless otherwise stated) using a Neslab RTE-111 circulating water bath. Measurements were made over various time courses between 0.2 and 200 s, collecting 1000 data points with oversampling activated. Excitation wavelengths of 280 or $295 \mathrm{~nm}$ were selected by a monochromator and fluorescence emission above $335 \mathrm{~nm}$ was selected using a cut-off filter. All solutions were prepared in filtered and degassed $20 \mathrm{~mm}$ potassium phosphate buffer, $\mathrm{pH}$ 8.0. Each reaction was carried out in triplicate and the data averaged and analyzed using the manufacturer's software and single or double exponential curve fitting algorithms.

For the determination of the rate constants for the association and dissociation of the complex, the concentration of $\kappa$-chain was kept at 1.5 $\mu \mathrm{M}$, and the concentrations of the $\mathrm{PpL}_{3316}$ mutants were varied between 10 and $50 \mu \mathrm{M}$. Alternatively, in some experiments the concentration of $\mathrm{PpL}_{3316}$ was kept constant at $1.5 \mu \mathrm{M}$, and the concentration of $\kappa$-chain was varied.

To study the rate of dissociation of the complexes formed between $\mathrm{PpL}_{3316}$ mutants and $\kappa$-chain, a solution containing a preformed complex ( $3 \mu \mathrm{M} \kappa$-chain and $3 \mu \mathrm{M}$ mutant $\mathrm{PpL}_{3316}$ ) was rapidly diluted by an equal volume of the non-fluorescent (above $335 \mathrm{~nm}) \mathrm{wt} \mathrm{PpL}_{3316}(30 \mu \mathrm{M})$. All concentrations quoted are final concentrations after 1:1 v/v mixing.

Sequential Mixing Stopped-flow Fluorimetry-To identify any intermediate complexes in the formation of the equilibrium complex between the $\mathrm{PpL}_{3316}$ and $\kappa$-chain, the stopped-flow fluorimeter was reconfigured to facilitate sequential mixing. Initially $6 \mu \mathrm{M}$ Trp-labeled $\mathrm{PpL}_{3316}$ (i.e. $\mathrm{I} 34 \mathrm{~W}$ or $\mathrm{Y} 64 \mathrm{~W} \mathrm{PpL}_{3316}$ ) was mixed with an equal volume of $6 \mu \mathrm{M}$ $\kappa$-chain. After a delay to allow complex formation ( $50 \mathrm{~ms}$ to $50 \mathrm{~s}$ ), the 3 $\mu \mathrm{M}$ Trp-labeled $\mathrm{PpL}_{3316}, 3 \mu \mathrm{M} \kappa$-chain solution was mixed with an equal volume of $30 \mu \mathrm{M}$ wt $\mathrm{PpL}_{3316}$ in $20 \mathrm{~mm}$ potassium phosphate buffer, $\mathrm{pH}$ 8.0, causing dissociation of the Trp labeled $\mathrm{PpL}_{3316^{\circ}} \kappa_{\text {-chain }}$ complex. Upon initiation of the second mixing step, fluorescence emissions above $335 \mathrm{~nm}$ were monitored over appropriate time courses.

Isothermal Titration Calorimetry-Isothermal titration calorimetry was carried out using a Microcal VP-ITC at $15^{\circ} \mathrm{C}$, with protein solu- (a)

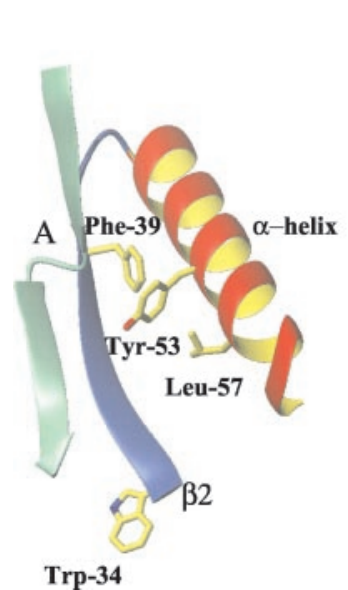

(b)

$\beta 3$

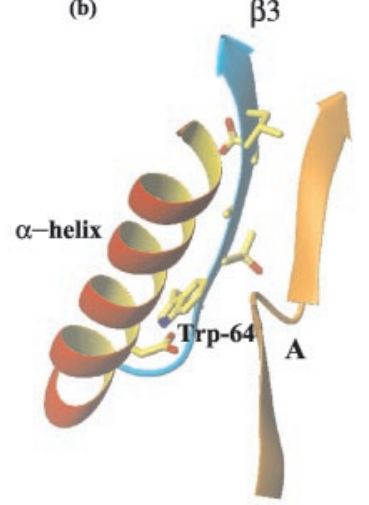

FIG. 1. Ribbon diagrams of showing features of mutated $\mathbf{P p L}_{\mathbf{3 3 1 6}}$ domains. $a$, the positions of the $\mathrm{I} 34 \mathrm{~W}, \mathrm{Y} 53 \mathrm{~F}$, and $\mathrm{L} 57 \mathrm{H}$ mutations in site 1 and their relative positions to $\beta$-strand $\mathrm{A}$ of bound $\kappa$-chain. $b$, the position of $\mathrm{Y} 64 \mathrm{~W}$ (site 2 ) and its relationship to $\beta$-strand A of bound $\kappa$-chain.

tions prepared in $20 \mathrm{~mm}$ potassium phosphate buffer, $\mathrm{pH}$ 8.0. The interaction of wt $\mathrm{PpL}_{3316}$ with $\kappa$-chain was studied through the titration of aliquots of $360 \mu \mathrm{M} \kappa$-chain into $15 \mu \mathrm{M}$ wt $\mathrm{PpL}_{3316}$. Heat changes associated with the dilution of the $\kappa$-chain were measured by the titration of aliquots of $360 \mu \mathrm{M} \kappa$-chain into $20 \mathrm{~mm}$ potassium phosphate buffer, $\mathrm{pH}$ 8.0. The enthalpy profile for the control titration into buffer was subtracted from the experimental data, with the resulting binding data being analyzed using the manufacturer's software.

To further resolve the binding interactions of $\kappa$-chain at sites 1 and 2 of $\mathrm{PpL}_{3316}$, mutant $\mathrm{PpL}_{3316}$ constructs with site 2 or site 1 eliminated (737 and $650 \mu \mathrm{M}$, respectively) were titrated into $\kappa$-chain (28.3 and 25 $\mu \mathrm{M}$, respectively). As above, binding data from these titrations were analyzed using the manufacturer's software.

Circular Dichroism - CD measurements were made using a Jasco J-720 CD spectrometer thermostated at $15^{\circ} \mathrm{C}$. The spectra between 195 and $250 \mathrm{~nm}$ were measured at a scan rate of $50 \mathrm{~nm} / \mathrm{min}$ using a $1-\mathrm{mm}$ path length. The spectra were scanned in triplicate, with a response time of $4 \mathrm{~s}$, slitwidth of $500 \mu \mathrm{m}$, bandwidth of $1.0 \mathrm{~nm}$, and resolution of $0.2 \mathrm{~nm}$. Spectral corrections and calculations were carried out using the manufacturer's software, and the units are given in mean residue ellipticity.

\section{RESULTS AND DISCUSSION}

Changes in the environment of the Trp reporter groups were examined by comparing the emission spectra of $1.5 \mu \mathrm{M} \kappa$-chain and $1.5 \mu \mathrm{M}$ of each of the $\mathrm{PpL}_{3316}$ mutants, in free solution and complex, using excitation wavelengths of 280 and $295 \mathrm{~nm}$. The spectra showed that $\operatorname{Trp}^{64}$ and $\operatorname{Trp}^{34}$ have wavelengths of maximum emission at 335 and $345 \mathrm{~nm}$, respectively, indicating that $\operatorname{Trp}^{64}$ is in a more hydrophobic environment than $\operatorname{Trp}^{34}$. The latter points downwards from $\beta$-strand 2 into the solvent and away from the center of the domain, whereas the side chain of $\operatorname{Trp}^{64}$ is surrounded by side chains from the $\alpha$-helix and $\beta$-strand 2 (see Fig. 1). No detectable shift in position of maximum emission is noted for the $\mathrm{Y} 64 \mathrm{~W} \mathrm{PpL}_{3316^{\circ}} \kappa$-chain complex; however, a 5 -nm blue shift is seen with the $\mathrm{I} 34 \mathrm{~W} \mathrm{PpL}_{3316^{\circ}}$ chain complex suggesting that $\operatorname{Trp}^{34}$ becomes less solvent exposed on complex formation. Details of the spectral characteristics of the various $\mathrm{PpL}_{3316^{\circ}} \kappa$-chain complexes, and the same proteins in free solution are given in Tables I and II. The data show that both the I34W and $\mathrm{Y} 64 \mathrm{~W} \mathrm{PpL}_{3316}$ domains exhibit fluorescence intensity changes upon complex formation with $\kappa$-chain. The intensity of $\operatorname{Trp}^{34}$ decreases significantly whether excited at 280 or $295 \mathrm{~nm}$, whereas that of $\operatorname{Trp}^{64}$ increases slightly when excited at $295 \mathrm{~nm}$ but decreases when excited at $280 \mathrm{~nm}$.

The respective distances of these residues from $\mathrm{Tyr}^{53}$ are $\sim 10 \AA$ and $15 \AA$, respectively, well within the critical distance 
TABLE I

Fluorescence spectral characteristics of various $P p L_{3316}$ domains and their complexes with $\kappa_{1}$-chain $\left(\lambda_{e x}=280 \mathrm{~nm}\right)$

\begin{tabular}{|c|c|c|c|}
\hline \multirow[b]{2}{*}{$\mathrm{PpL}$ construct } & \multicolumn{2}{|c|}{ Wavelength of emission maximum } & \multirow[b]{2}{*}{$\Delta$ Fluorescence } \\
\hline & $\mathrm{PpL}+\kappa$-chain & $\begin{array}{l}\text { PpL·k-chain } \\
\text { complex }\end{array}$ & \\
\hline & \multicolumn{2}{|c|}{$n m$} & $\%$ \\
\hline Y64W & 335 & 335 & -8.6 \\
\hline Y64W/Y53F & 335 & 335 & +18.6 \\
\hline I34W & 345 & 340 & -16.9 \\
\hline I34W/Y53F & 345 & 343 & -6.8 \\
\hline
\end{tabular}

TABLE II

Fluorescence spectral characteristics of various $P p L_{3316}$ domains and their complexes with $\kappa_{1}$-chain $\left(\lambda_{e x}=295 \mathrm{~nm}\right)$

\begin{tabular}{lccc}
\hline \multirow{2}{*}{$\mathrm{PpL}_{3316}$ construct } & \multicolumn{2}{c}{ Wavelength of emission maximum } & \\
\cline { 2 - 3 } & $\mathrm{PpL}_{3316}+\kappa$-chain & $\begin{array}{c}\mathrm{PpL}_{3316}{ }^{*} \text {-chain } \\
\text { complex }\end{array}$ & $\Delta$ Fluorescence \\
& \multicolumn{3}{c}{$n m$} \\
Y64W & 335 & 335 & $\%$ \\
Y64W/Y53F & 335 & 335 & +11.6 \\
I34W & 345 & 340 & +49.9 \\
I34W/Y53F & 345 & 344 & -1.9 \\
\hline
\end{tabular}

for efficient Förster fluorescence resonance energy transfer (FRET), and $\operatorname{Trp}^{64}$ and $\operatorname{Trp}^{34}$ are almost certainly excited due to resonance energy transfer from this residue. Previous studies have shown the fluorescence of $\mathrm{Tyr}^{53}$ is quenched upon complex formation with $\kappa$-chain (9), and therefore the component of $\operatorname{Trp}^{64}$ or $\operatorname{Trp}^{34}$ fluorescence arising due to FRET from $\mathrm{Tyr}^{53}$ (when excited at $280 \mathrm{~nm}$ ) will also decrease. The changes in intensity, and the location of the two Trp groups, 34 and 64, close to site 1 and in site 2 , respectively, support the concept of $\kappa$-chain binding at both sites.

It should be noted that no fluorescence intensity changes (excited by light at $295 \mathrm{~nm}$ ) occur when $\kappa$-chain is mixed with the $\mathrm{I} 34 \mathrm{~W} / \mathrm{Y} 53 \mathrm{~F} / \mathrm{L} 57 \mathrm{H}$ or $\mathrm{Y} 64 \mathrm{~W} / \mathrm{A} 66 \mathrm{~W} \mathrm{PpL}_{3316}$ proteins (data not shown) suggesting that binding does not take place at site 1 or site 2 of these mutants, respectively. However, a decrease in fluorescence intensity at $335 \mathrm{~nm}$ or above does occur when $\kappa$-chain binds to $\mathrm{Y} 64 \mathrm{~W} / \mathrm{A} 66 \mathrm{~W} \mathrm{PpL}_{3316}$, and an excitation wavelength of $280 \mathrm{~nm}$ is employed. This is almost certainly due to decreased FRET from $\operatorname{Tyr}^{53}$ to $\operatorname{Trp}^{64}$ when $\kappa$-chain occupies site 1 (see above).

The largest change in fluorescence intensity occurs when Y64W/Y53F PpL $\mathrm{P}_{3316}$ forms a complex with $\kappa$-chain $(\lambda \mathrm{ex}=280$ $\mathrm{nm}$ or $295 \mathrm{~nm}$ ). The Y53F mutation (site 1) has a clear effect on the fluorescence properties of $\mathrm{Y} 64 \mathrm{~W}$ in site 2 . This could be due to a direct spectral perturbation (although the expected effect would be a decrease in fluorescence intensity from Y64W when excited at $280 \mathrm{~nm}$, see above) or more probably a consequence of the decrease in affinity at site 1 caused by this mutation (9).

Under the conditions of the above experiments there is only sufficient $\kappa$-chain to form a 1:1 mol:mol complex with $\mathrm{PpL}_{3316}$. As a result, sites 1 and 2 are both competing for the available $\kappa$-chain, with the amount bound to each site being dependent upon the relative affinities of the sites. Therefore, any mutation (e.g. Y53F) that causes a decrease in the amount of $\kappa$-chain bound at site 1 will lead to a concomitant increase in $\kappa$-chain available to bind to site 2 and thus have an effect on the magnitude of the signal change from either $\operatorname{Tr} p^{34}$ or $\operatorname{Trp}{ }^{64}$.

Pre-equilibrium Binding Studies-Stopped-flow fluorescence techniques were used to study the binding reactions between mutant $\mathrm{PpL}_{3316}$ proteins and $\kappa$-chain. They illustrated that the observed fluorescence changes that occur for the Y64W/Y53F, $\mathrm{Y} 64 \mathrm{~W}, \mathrm{I} 34 \mathrm{~W} / \mathrm{Y} 53 \mathrm{~F}$, and I34W mutants seen above are in fact the net results of more complex changes (Fig. 2).
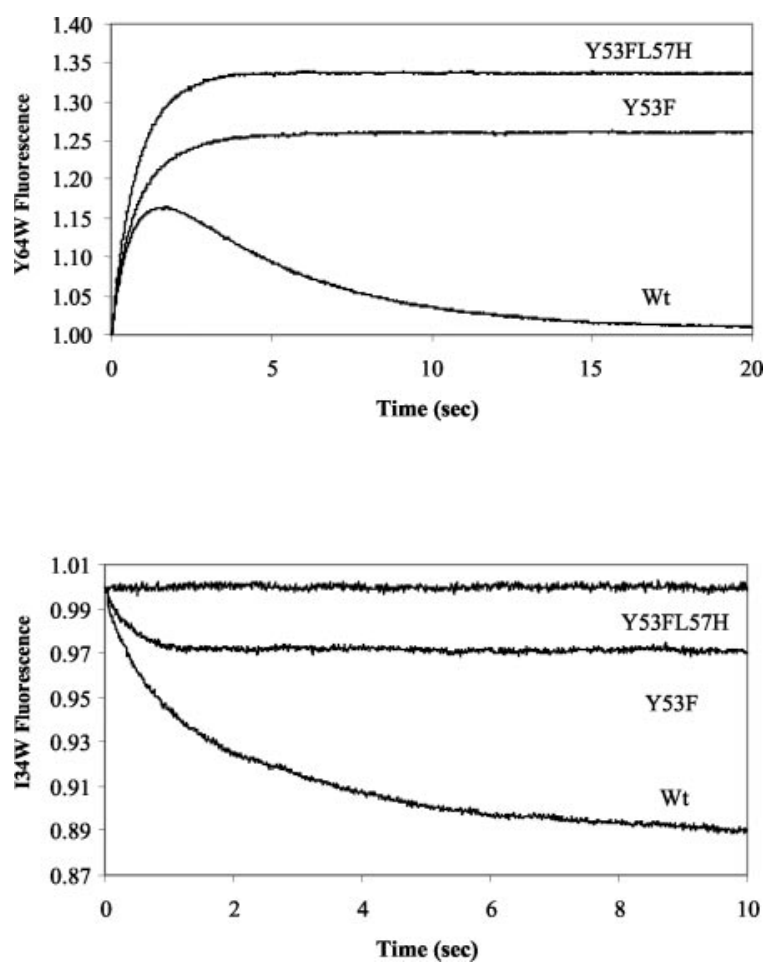

FIG. 2. Reaction progress curves showing the changes in fluorescence intensity observed upon mixing $\kappa$-chain with various $\mathbf{P p L}_{3316}$ mutants. $1.5 \mu \mathrm{M}$ k-chain was mixed with $1.5 \mu \mathrm{M} \mathrm{PpL}_{3316}$ mutant (Y64W/Y53F/L57H, Y64W/Y53F, Y64W, I34W/Y53F/L57H, I34W/Y53F, or I34W as indicated) in $20 \mathrm{~mm}$ potassium phosphate buffer, $\mathrm{pH} 8.0$ at $15{ }^{\circ} \mathrm{C}$. The fluorescence values shown are relative to the initial fluorescence observed for each reaction. Concentrations quoted are after mixing.

The single mutation $\mathrm{Y} 64 \mathrm{~W}$ produces a domain that shows large and complex changes in fluorescence when mixed with $\kappa$-chains. When excited at $280 \mathrm{~nm}$ a rapid increase in fluorescence intensity is followed by a slow and larger decrease. The binding of I34W to $\kappa$-chain under these conditions also appears to be a two-step process, both steps being accompanied by a decrease in fluorescence intensity. Biphasic kinetics such as these have been observed previously and occur when the mutant F39W $\mathrm{PpL}_{3316}$ is mixed with $\kappa$-chain (9). The unidirectional, biphasic fluorescence intensity changes observed in those studies are consistent with a system in which the rapid fluorescence change corresponds to the formation of an encounter complex that subsequently undergoes a slower local rearrangement from a low affinity complex to a high affinity equilibrium complex. However, this model cannot explain the reaction progress curves that show more complex bidirectional fluorescence changes. In view of the recent crystallographic results that detail the existence of a second, albeit much weaker, binding site for $\kappa$-chain on $\mathrm{PpL}_{3316}$, we can now reconcile these data with a two-site binding model. This model not only explains the complex fluorescence changes described above but also allows the $K_{d}$ for the two binding sites to be determined.

In this model $\kappa$-chains bind independently to sites $1\left(^{1}\right)$ and 2 $\left.{ }^{2}\right)$ on ${ }^{1} \mathrm{PpL}^{2}$. The overall $K_{d}$ for each site will depend upon the ratios of their dissociation $\left(k_{-1}\right.$ and $\left.k_{-2}\right)$ and association rate constants $\left(k_{1}\right.$ and $\left.k_{2}\right)$, respectively. Thus if the two sites have different $K_{d}$ values for their respective complexes with $\kappa$-chains and the rates of association of $\kappa$-chain to the two sites are similar, then the rates of dissociation from these sites must be different. Such a phenomenon (17) will explain the biphasic fluorescence changes described above. For example, consider 


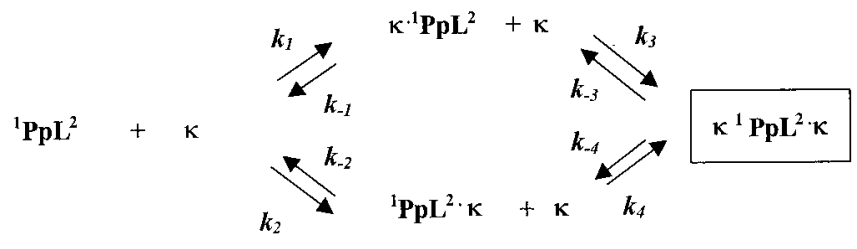

Scheme 1. Two-site binding model.

the situation when $\mathrm{PpL}_{3316}$ is present in excess and the rates of association to each site are similar. Under these conditions the $\kappa$-chain will initially bind to both sites 1 and 2 . However, if site 2 has a higher dissociation rate than site 1 the occupancy of site 2 decreases and the $\kappa$-chain is redistributed in favor of site 1 . Thus a reporter group in site $2, e . g$. $\operatorname{Trp}^{64}$, may show an initial fluorescence increase, as it becomes less solvent exposed due to the binding of $\kappa$-chain, followed by a decrease in fluorescence as the $\kappa$-chain is redistributed in favor of site 1 . Similarly, the site 1 reporter group F39W shows a biphasic change on complex formation. In this case an initial rapid increase in fluorescence intensity, due to binding of free $\kappa$-chain to this site, followed by a slower increase, due to the further saturation of available site 1 a consequence of $\kappa$-chain being released from site 2 . This is in accord with previous data (9). An alternative reporter group in site 1 , I34W, which lies on the opposite side of $\beta$ strand 2 and points away from the helix, interestingly shows a biphasic decrease in fluorescence on formation of a complex with $\kappa$-chain.

If the binding of $\kappa$-chain to each site is independent of the presence of $\kappa$-chain at the other site, then rates $k_{1}, k_{-1}, k_{2}$, and $k_{-2}$ will be the same as rates $k_{4}, k_{-4}, k_{3}$, and $k_{-3}$, respectively. However, in the presence of excess $\mathrm{PpL}_{3316}$ the complex involving one $\mathrm{PpL}_{3316}$ domain and two $\kappa$-chains $\left(\kappa^{1}{ }^{1} \mathrm{PpL}^{2} \cdot \kappa\right.$, shown boxed in Scheme 1) will not be present in significant amounts.

This model is supported by the dramatic effects of the additional mutation Y53F on the fluorescence properties and the reaction progress curves observed on complex formation. It virtually eliminates the second, slow decrease in fluorescence intensity shown by $\operatorname{Trp}^{64}$ (Fig. 2) and is almost certainly attributable to the decreased affinity of site 1 , a result of the Y53F replacement (9). Thus if the affinity of site 1 is decreased to, or below that, of site 2 , then under the conditions used, more $\kappa$-chain will remain bound to site 2 , and the fluorescence intensity at equilibrium from $\operatorname{Trp}^{64}$ will be higher. This conclusion is supported by experiments using the mutant I34W/Y53F. This protein gives a reaction progress curve that appears to have a single-phase fluorescence change with a decreased amplitude compared with that observed for the binding of the single mutant I34W to $\kappa$-chain. These observations are consistent with the idea that the Y53F mutation reduces the affinity of site 1 close to that of site 2 .

Finally, I34W/Y53F/L57H $\mathrm{PpL}_{3316}$ containing the binding site mutations Y53F/L57H with the site 1 reporter $\operatorname{Trp}^{34}$ shows no fluorescence change when mixed with $\kappa$-chain. This is because binding at site 1 has been substantially reduced/eliminated, and any significant remaining $\kappa$-chain binding is due to site 2 . This is supported by the results gained from experiments using the same site mutations but with the Y64W reporter (Y64W/Y53F/L57H PpL $\mathrm{P}_{3316}$ ). This domain binds $\kappa$-chain resulting in the largest increase in fluorescence intensity (see Fig. 2). Assuming that the spectral response of the $\operatorname{Trp}^{64}$ reporter group, excited by light at $295 \mathrm{~nm}$, is not affected directly by the substitutions on the opposite side of the domain, these data suggest that the fluorescence intensity of $\mathrm{Y} 64 \mathrm{~W} \mathrm{PpL}_{3316}$ at equilibrium reflects the occupancy of site 2 only. Thus the large fluorescence change given by $\mathrm{Y} 64 \mathrm{~W} / \mathrm{Y} 53 \mathrm{~F} / \mathrm{L} 57 \mathrm{H}$ and the ab-
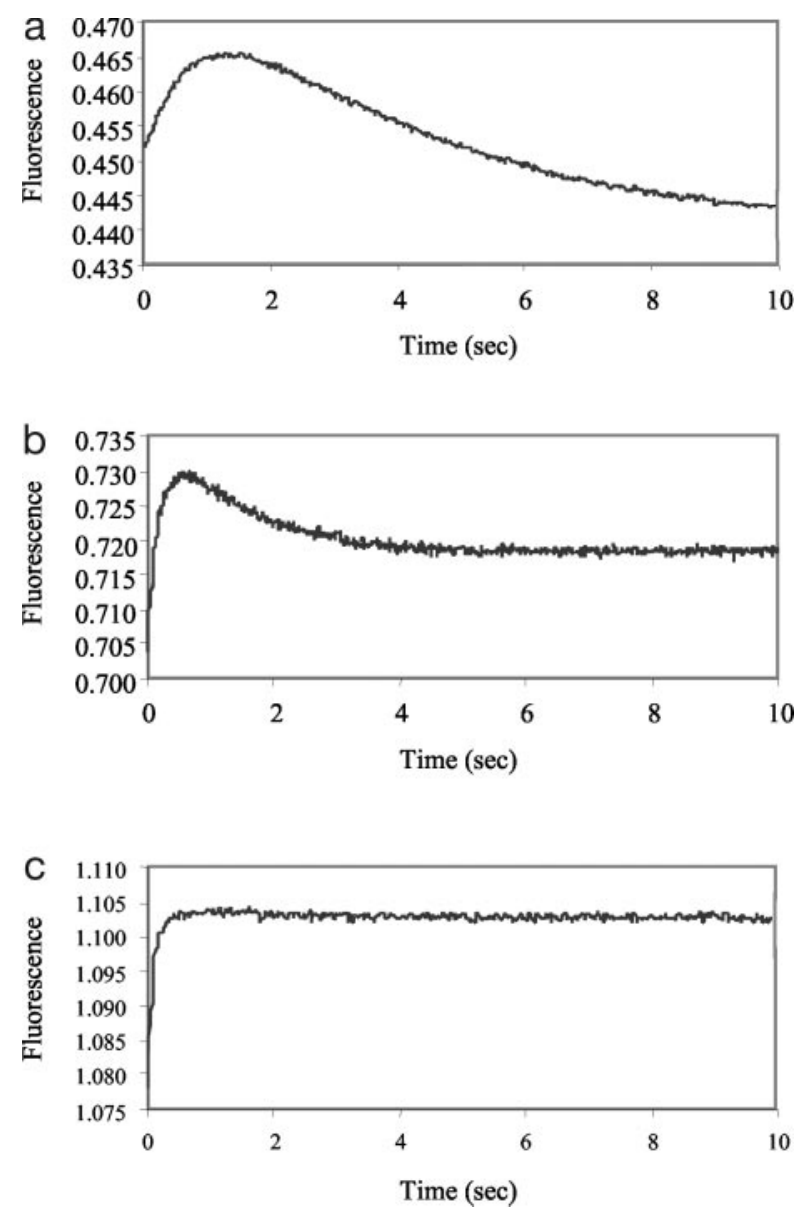

FIG. 3. Reaction progress curves showing the changes in fluorescence intensity observed upon reaction between $\mathrm{Y} 64 \mathrm{~W}$ $\mathbf{P p L}_{3316}$ and $\kappa$-chain. The reaction was initiated by mixing $1.5 \mu \mathrm{M}$ Y64W PpL 3316 with $1.8 \mu \mathrm{M} \kappa$-chain $(a), 9.9 \mu \mathrm{M} \kappa$-chain (b), and $28.8 \mu \mathrm{M}$ $\kappa$-chain (c) in $20 \mathrm{~mm}$ potassium phosphate buffer, $\mathrm{pH} 8.0$ at $15^{\circ} \mathrm{C}$. Concentrations quoted are after mixing.

sence of any fluorescence change for the same reaction with I34W/Y53F/L57H support the proposal that all of the bound $\kappa$-chain is located at site 2 .

If the binding model described in the above scheme is correct then one would expect to see different reaction progress curves when the experiment is repeated with increasing concentrations of $\kappa$-chain. Eventually there will be sufficient $\kappa$-chain to occupy both binding sites to give the species $\kappa^{1} \mathrm{PpL}^{2} \cdot \kappa$, and thus the reaction progress curves will become monophasic. Such an experiment is described in Fig. 3, which displays three reaction curves in which $1.5 \mu \mathrm{M} \mathrm{Y} 64 \mathrm{~W} \mathrm{PpL}_{3316}$ is mixed with $1.8,9.9$, and $28.8 \mu \mathrm{M} \kappa$-chain. There is a clear reduction in the amplitude of the slow decrease in fluorescence as the concentration of $\kappa$-chain is increased. This reflects the increased occupancy of site 2 at equilibrium due to the higher concentration of $\kappa$-chain.

Do the Mutations Alter the Structure of the PpL Domain?Circular dichroism studies (see Fig. 4) have shown that wt, L57H, Y53F, and Y53F/L57H domains have identical far UV CD spectra suggesting that the substitutions have not disturbed the secondary structures of the proteins. The presence of Trp residues in position 34 or 64 leads to an increase in ellipticity between 205 and $210 \mathrm{~nm}$ that is almost certainly due to spectral contributions from the aromatic side chains rather than disruption of the secondary folding of the protein. Furthermore, the structure of $\mathrm{Y} 64 \mathrm{~W}$ obtained by $\mathrm{x}$-ray studies shows no significant backbone differences to that of the wt $\mathrm{PpL}_{3316}$ (18). Further mutations, e.g. Y53F, L57H, or Y53F/ 


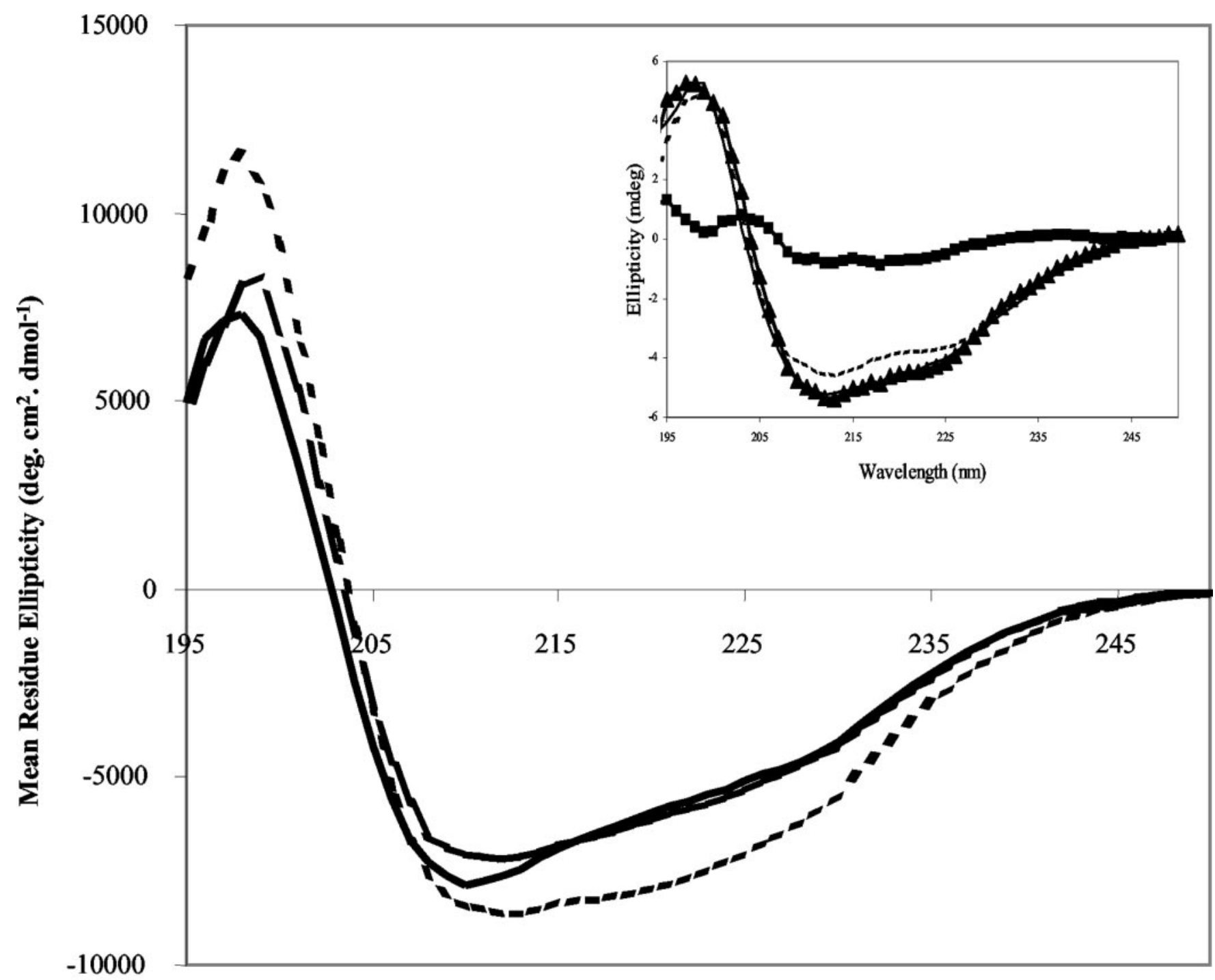

\section{W a velength (n m)}

FIg. 4. Far-UV CD spectra of wt, I34W, and Y64W $\mathbf{P p L}_{\mathbf{3 3 1 6}}$. The spectra shown are each the average of three scans using $20 \mu \mathrm{M} \mathrm{wt} \mathrm{PpL}_{3316}$ (dashed line), Y64W (solid line), or I43W (dotted line) in $20 \mathrm{~mm}$ potassium phosphate buffer, $\mathrm{pH} 8.0,15^{\circ} \mathrm{C}$. The inset shows the spectrum of $20 \mu \mathrm{M}$

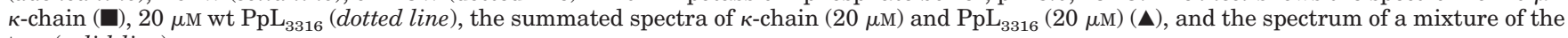
two (solid line).

L57H made to the I34W or Y64W domains, caused no further spectral changes again indicating that they do not disrupt the folding of $\mathrm{PpL}_{3316}$.

Does the Binding Reaction Involve a Change in Structure of the Complex? - The determination of the x-ray crystallographic structures of the complexes between wt $\mathrm{PpL}_{3316}$ and a human Fab (10) and Y64W $\mathrm{PpL}_{3316}$ and a mouse Fab (18) have shown that the secondary structure of the free $\mathrm{PpL}_{3316}$ is the same as that of $\mathrm{PpL}_{3316}$ in the complex. Furthermore, the far-UV CD spectrum of wt $\mathrm{PpL}_{3316}$ is the same in the absence or presence of an equimolar concentration of $\kappa$-chain (see inset to Fig. 4) suggesting that there is no change in secondary structure on complex formation.

Determination of $K_{\mathrm{d}}$ for Complexes at Sites 1 and 2-By determining the rates $k_{1}, k_{-1}, k_{2}$, and $k_{-2}$ for $\kappa$-chain binding to sites 1 and 2 of $\mathrm{PpL}_{3316}$, respectively, the $K_{d}$ of the complex at each site can be determined. In experiments using domains with both sites functioning then the overall observed rate of association, $k_{a}$, will be a combination of the association rates for each site $\left(k_{1}+k_{2}\right.$, see Fig. 5$)$. Thus to determine the association rate to each site individually it was necessary to eliminate the alternative site in each case. This was achieved by the mutations $\mathrm{Y} 53 \mathrm{~F} / \mathrm{L} 57 \mathrm{H}$ and A66W on the I34W or Y64W templates. These remove binding capacity at sites 1 and 2, respectively. $k_{\alpha}$ can be calculated from the slope of a plot of the observed rate, $k_{\text {app }}$, against the concentration of the variable ligand $\left(\mathrm{PpL}_{3316}\right)$. Such data using various $\mathrm{PpL}_{3316}$ mutants are given in Table III. In the absence of $\kappa$-chain binding at site 1 the reaction of $\kappa$-chain with site 2 of the Y64W/Y53F/L57H $\mathrm{PpL}_{3316}$ mutant is a simple bimolecular binding process and the observed rate of reaction $k_{\text {app }}=k_{2}[\mathrm{Y} 64 \mathrm{~W} / \mathrm{Y} 53 \mathrm{~F} / \mathrm{L} 57 \mathrm{H}$ $\left.\mathrm{PpL}_{3316}\right]+k_{-2}$ (see Fig. 5). The variation of $k_{\text {app }}$ with varying concentrations of $\mathrm{Y} 64 \mathrm{~W} / \mathrm{Y} 53 \mathrm{~F} / \mathrm{L} 57 \mathrm{H} \mathrm{PpL} \mathrm{P}_{3316}$ is shown in the inset to Fig. 5, and the value of $k_{2}$ is $0.15 \pm 0.02 \mu \mathrm{M}^{-1} \mathrm{~s}^{-1}$ (Table III). Similarly experiments show that $k_{1}$ for binding at site 1 (using the mutant I34W/A66W) is $0.25 \pm 0.01 \mu \mathrm{M}^{-1} \mathrm{~s}^{-1}$ at $25^{\circ} \mathrm{C}$. The sum of these two association rate constants $\left(0.40 \mu \mathrm{M}^{-1} \mathrm{~s}^{-1}\right)$ is very close to that determined for domains in which binding occurs to both sites simultaneously, as described above, e.g. Y64W $\left(0.35 \pm 0.03 \mu \mathrm{M}^{-1}\right.$ $\left.\mathrm{s}^{-1}\right)$ or I34W $\left(0.33 \pm 0.02 \mu \mathrm{M}^{-1} \mathrm{~s}^{-1}\right)$. 


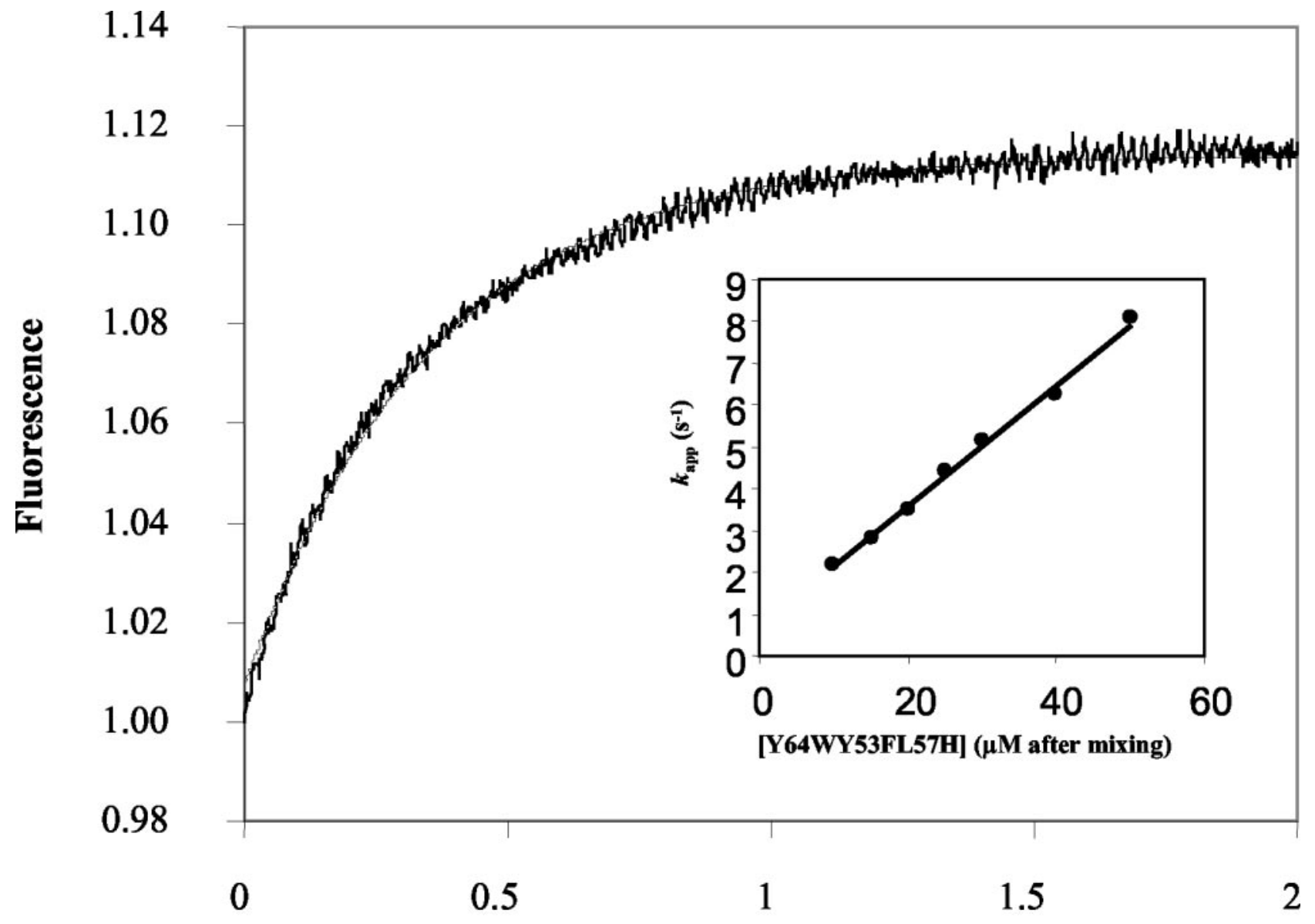

\section{Time (sec)}

FIG. 5. A reaction progress curve showing the changes in fluorescence intensity observed upon the reaction between $\kappa$-chain and Y64W/Y53F/L57H PpL 3316 . Both proteins (1.5 $\mu \mathrm{M} \kappa$-chain and $15 \mu \mathrm{M} \mathrm{PpL} \mathrm{P}_{3316}$ after mixing) were dissolved in $20 \mathrm{~mm}$ potassium phosphate buffer, $\mathrm{pH}$ 8.0. Inset, the variation of $k_{\text {app }}$ upon mixing $1.5 \mu \mathrm{M} \kappa$-chain with various concentrations of Y64W/Y53F/L57H PpL $\mathrm{P}_{3316}$.

TABLE III

The rates of association, dissociation, and $K_{d}$ values for the various $P p L_{3316^{*}}{ }^{\kappa}$-chain complexes $(n=3)$

Standard deviations are only given for experimentally determined values. ND is given where no reporter group is present in the respective site to be determined.

\begin{tabular}{|c|c|c|c|c|c|c|c|}
\hline \multirow{2}{*}{ PpL construct } & \multirow{2}{*}{$k_{a}$} & \multicolumn{3}{|c|}{ Site 1} & \multicolumn{3}{|c|}{ Site 2} \\
\hline & & $k_{1}$ & $k_{-1}$ & $K_{d}$ & $k_{2}$ & $k_{-2}$ & $K_{d}$ \\
\hline & $M^{-1} s^{-1} \times 10^{4}$ & $M^{-1} s^{-1} \times 10^{4}$ & $s^{-1} \times 10^{-3}$ & $M \times 10^{-9}$ & $M^{-1} s^{-1} \times 10^{4}$ & $s^{-1} \times 10^{-3}$ & $M \times 10^{-7}$ \\
\hline Y64W & $35 \pm 3$ & $20^{a}$ & $8 \pm 1$ & 38 & $15^{b}$ & $560 \pm 20$ & 37 \\
\hline Y64W/Y53F & $33 \pm 6$ & $18^{a}$ & ND & ND & $15^{b}$ & $410 \pm 30$ & 28 \\
\hline Y64W/Y53F/L57H & $15 \pm 2$ & \multicolumn{3}{|c|}{ No detectable binding } & $15 \pm 2$ & $500 \pm 20$ & $34 \pm 7$ \\
\hline I34W & $33 \pm 2$ & $18^{a}$ & $13 \pm 1$ & 68 & $15^{b}$ & ND & ND \\
\hline I34W/Y53F & $33 \pm 3$ & $18^{a}$ & $840 \pm 13$ & 4400 & $15^{b}$ & ND & ND \\
\hline I34W/A66W & $25 \pm 1$ & $25 \pm 1$ & $12 \pm 1$ & $48 \pm 8$ & No & ectable bind & \\
\hline
\end{tabular}

${ }^{a}$ Values of $k_{1}$ calculated by subtraction of $k_{2}$ (determined for the Y64W/Y53F/L57H- $\kappa$-chain interaction) from $k_{a}$ (the combined rates of $k_{1}$ and $k_{2}$ ).

${ }^{b}$ The value of $k_{2}$ determined from experiments using Y64W/Y53F/L57H PpL in which binding at site 1 has been eliminated.

To corroborate these calculations we used domains with the $\operatorname{Trp}^{34}$ reporter and determined $k_{1}$ and $k_{-1}$ for the reaction by rapidly mixing a constant amount of the $\mathrm{PpL}_{3316}$ domain with various excess concentrations of $\kappa$-chain, the latter always in large excess so that pseudo-first order conditions can be achieved. The observed rate of reaction $k_{\text {app }}$ will depend upon the concentration of $\kappa$-chain, and a plot of $k_{\text {app }}$ against $\kappa$-chain concentration yielded a line of slope $k_{1}$, in this case $0.23 \pm 0.04 \mu \mathrm{M}^{-1} \mathrm{~s}^{-1}$ (data not shown), which is in close agreement with the values determined by other methods (see Table III).
Determination of the Rates of Dissociation of the ComplexesAlthough estimates of the dissociation rates $k_{-1}$ or $k_{-2}$ can be obtained from the intercept on the ordinate of the plot shown in the inset to Fig. 5, these are prone to large errors when their values are so low (19). Therefore rates of dissociation of the complexes between $\mathrm{PpL}_{3316}$ domains and $\kappa$-chain were measured as described under "Experimental Procedures," and the data are summarized in Fig. 6, $a-c$, and Table III. The dissociation of the $\kappa$-chain from the complex at site 1 of I34W $\mathrm{PpL}_{3316}$ gives rise to a slow, single-phase fluorescence increase, with a rate of $0.013 \pm 0.001 \mathrm{~s}^{-1}$. The rate of dissociation of the 

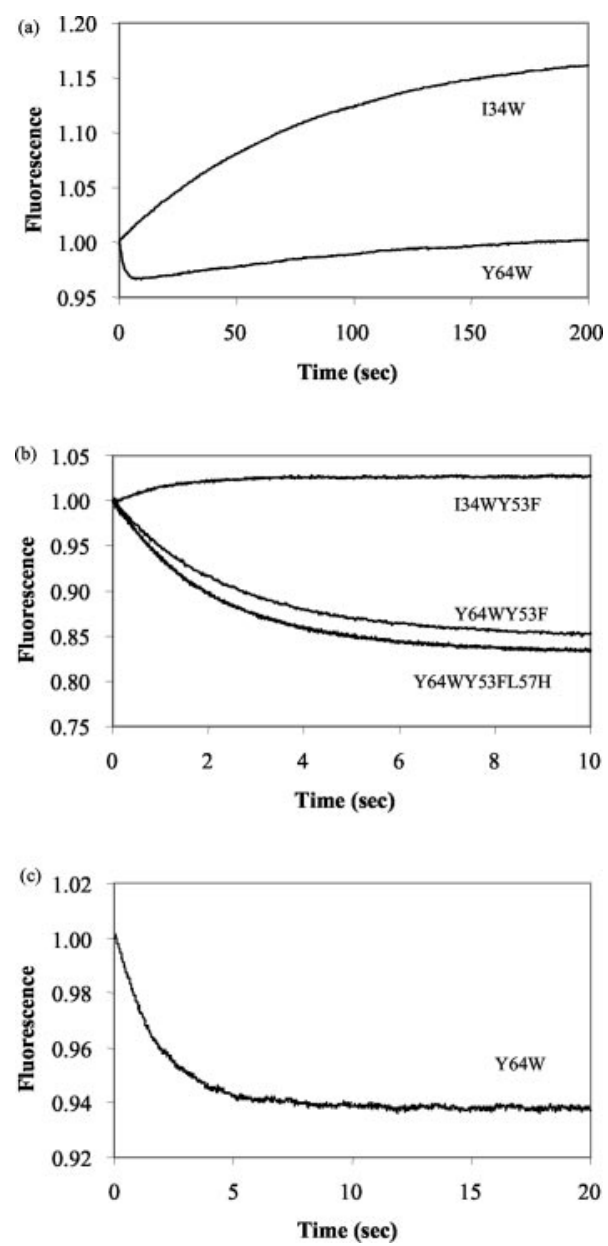

FIG. 6. Fluorescence intensity changes observed upon the dissociation of $\mathrm{PpL}_{3316^{\cdot}} \mathrm{k}$-chain complexes at $\mathrm{pH} 8.0$ and $15{ }^{\circ} \mathrm{C} . a$, emission at wavelengths greater than $335 \mathrm{~nm}$, using an excitation wavelength of $280 \mathrm{~nm}$, observed upon the dissociation of the I34W $\mathrm{PpL}_{3316}{ }^{*}$-chain and $\mathrm{Y} 64 \mathrm{~W} \mathrm{PpL}_{3316^{\circ}} \kappa$-chain complexes. $b$, emission at wavelengths greater than $335 \mathrm{~nm}$, using an excitation wavelength of $280 \mathrm{~nm}$, upon dissociation of the I34WY53F $\mathrm{PpL}_{3316^{\circ}} \kappa$-chain, Y64W/ $\mathrm{Y} 53 \mathrm{~F}, \mathrm{PpL}_{3316^{*}} \kappa^{-c h a i n}$, and $\mathrm{Y} 64 \mathrm{~W} / \mathrm{Y} 53 \mathrm{~F} / \mathrm{L} 57 \mathrm{H} \mathrm{PpL}{ }_{3316^{\circ}} \kappa$-chain complexes. $c$, emission at wavelengths greater than $335 \mathrm{~nm}$, using an excitation wavelength of $295 \mathrm{~nm}$, upon dissociation of the Y64W $\mathrm{PpL}_{3316^{*}}{ }^{*}$-chain complex.

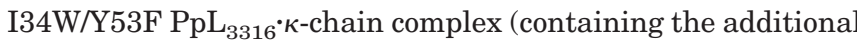
Y53F mutation) is $\sim 65$-fold greater $\left(0.84 \pm 0.01 \mathrm{~s}^{-1}\right)$, thus giving rise to a large increase in the value of $K_{d}$ (see Table III) as noted previously (9).

The fluorescence changes that accompany the dissociation of the $\mathrm{Y} 64 \mathrm{~W} \mathrm{PpL}_{3316^{\circ}} \kappa$-chain complex can be resolved into two distinct steps when an excitation wavelength of $280 \mathrm{~nm}$ is used. A fluorescence decrease occurs with a rate of $0.56 \pm 0.02 \mathrm{~s}^{-1}$, followed by a much slower fluorescence increase with a rate of $0.008 \pm 0.001 \mathrm{~s}^{-1}$, the latter of which is comparable with the

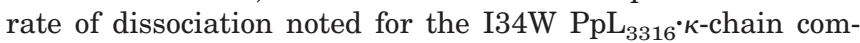
plex. The dissociation of the $\mathrm{Y} 64 \mathrm{~W} / \mathrm{Y} 53 \mathrm{~F} \mathrm{PpL} \mathrm{P}_{3316^{\circ}} \kappa$-chain and $\mathrm{Y} 64 \mathrm{~W} / \mathrm{Y} 53 \mathrm{~F} / \mathrm{L} 57 \mathrm{H} \mathrm{PpL}_{3316}{ }^{\circ} \kappa$-chain complexes are both accompanied by single-phase fluorescence decreases with rates of $0.41 \pm 0.03 \mathrm{~s}^{-1}$ and $0.50 \pm 0.02 \mathrm{~s}^{-1}$, respectively. Thus by introducing the mutations $\mathrm{Y} 53 \mathrm{~F}$ or $\mathrm{Y} 53 \mathrm{~F} / \mathrm{L} 57 \mathrm{H}$ into the $\mathrm{Y} 64 \mathrm{~W}$ $\mathrm{PpL}_{3316}$ template the initial phase of dissociation of the

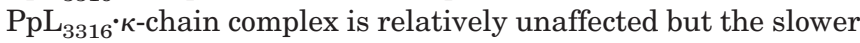
dissociation step is no longer observed suggesting this is due to dissociation from site 1 . The $K_{d}$ values for the complexes formed by the above $\mathrm{PpL}_{3316}$ domains and $\kappa$-chain are given in Table III.
When the dissociation experiment with the Y64W $\mathrm{PpL}_{3316^{\circ}} \kappa$-chain complex was repeated using an excitation wavelength of $295 \mathrm{~nm}$, only the initial fluorescence decrease was apparent (Fig. 6c). We can conclude from this that the initial fluorescence decrease is due to changes in the environment of $\operatorname{Trp}^{64}$ as the $\kappa$-chain dissociates from site 2 . The slower fluorescence change noted when the excitation wavelength is $280 \mathrm{~nm}$ arises from increased FRET from $\mathrm{Tyr}^{53}$ as the complex at site 1 dissociates (removing quenching from $\mathrm{Tyr}^{53}$ ). Therefore it is possible to simultaneously observe dissociation at sites 1 and 2 . Using the values of the rates of association $\left(k_{2}\right)$ and dissociation $\left(k_{-2}\right)$ of the Y64W/Y53F/ $\mathrm{L} 57 \mathrm{H} \mathrm{PpL} \mathrm{P}_{3316}{ }^{\circ} \kappa$-chain complex from the above experiments the $K_{d}$ at site 2 is $3.4 \pm 0.70 \mu \mathrm{M}$ (Table III).

Sequential Mixing Stopped-flow Fluorimetry-In the original single site binding model shown below (9), it was proposed that two structurally different forms of the $\mathrm{PpL}_{3316^{\circ}} \kappa$-chain complex exist.

$$
\mathrm{PpL}+\kappa \underset{k_{\text {diss }}}{\stackrel{k_{a}}{\rightleftarrows}} \mathrm{PpL} \cdot \kappa \underset{k_{r}}{\stackrel{k_{f}}{\rightleftarrows}}[\mathrm{PpL} \cdot \kappa]^{*}
$$

REACTION 1

In this scheme $k_{a}$ and $k_{\text {diss }}$ represent the rates of association and dissociation, respectively, of the encounter complex $\mathrm{PpL} \kappa$, and $k_{\mathrm{f}}$ and $k_{\mathrm{r}}$ represent the forward and reverse rates of the structural rearrangement, respectively.

In the proposed model (9) the transition from $\mathrm{PpL} \cdot \kappa$ to $[\mathrm{PpL} \cdot \kappa]^{*}$ was suggested to increase the affinity by $\sim 30$-fold. Thus under equilibrium conditions, the majority of the $\mathrm{PpL}$ and $\kappa$-chain would be present in the form of the high affinity complex. Also dissociation of the encounter complex occurs rapidly, while dissociation of the equilibrium complex is rate limited by $k_{\mathrm{r}}$ (9). Therefore upon dissociation of the complex at equilibrium most of the observed fluorescence change would occur with the rate $k r$. However, if dissociation of the $\mathrm{PpL} \cdot \kappa$-chain complex is invoked shortly after the mixing of $\mathrm{PpL}$ and $\kappa$-chain, before the encounter complex has undergone the structural rearrangement, the observed rate would be $k_{\text {diss }}$, that of the dissociation of the encounter complex. When both encounter and equilibrium complexes are present, the observed dissociation profile would be expected to be biphasic, the amplitude of each phase being dependent on the relative abundance of each complex.

However, sequential-mixing stopped-flow studies on the

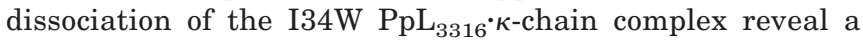
single-phase fluorescence increase upon dissociation. Regardless of the incubation time prior to initiation of dissociation, a rate constant of $\sim 0.01 \mathrm{~s}^{-1}$ was observed. Therefore, the

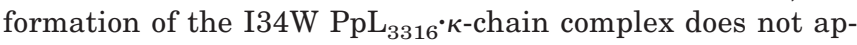
pear to occur by a two step process involving a structural rearrangement.

Isothermal Titration Calorimetry-Isothermal titration calorimetry was used to verify the $K_{d}$ values obtained for $\kappa$-chain binding to sites 1 and 2 of $\mathrm{PpL}_{3316}$ determined using the fluorimetric methods above. To attempt to resolve binding to sites 1 and $2, \kappa$-chain was titrated into wt $\mathrm{PpL}_{3316}$. As a result of the very high concentration of $\kappa$-chain required when used as the titrant the data required significant correction for the contribution to the enthalpy profile due to $\kappa$-chain dilution. The $K_{d}$ values for sites 1 and 2 were estimated to be $21.1 \pm 10.21 \mathrm{~nm}$ and $7.5 \pm 3.1 \mu \mathrm{M}$. respectively (see Table IV). The enthalpic contributions to binding at sites 1 and site 2 were $-54.3 \pm 0.7 \mathrm{~kJ} / \mathrm{mol}$ and $-28.1 \pm 6.2 \mathrm{~kJ} / \mathrm{mol}$, respectively, and the entropic changes were -41.4 and 0.7 $\mathrm{J} / \mathrm{mol} /$ degree, respectively. 
TABLE IV

Isothermal titration calorimetric analysis of $\kappa_{1}$-chain binding to sites 1 and 2 on $P p L_{3316} N=$ stoichiometry of binding sites $(n=3)$

\begin{tabular}{|c|c|c|c|c|c|c|c|c|}
\hline \multirow{2}{*}{$\mathrm{PpL}$} & \multicolumn{4}{|c|}{ Site 1} & \multicolumn{4}{|c|}{ Site 2} \\
\hline & $N$ & $K_{d}$ & $\Delta H$ & $\Delta S$ & $N$ & $K_{d}$ & $\Delta H$ & $\Delta S$ \\
\hline & & $n M$ & $\mathrm{~kJ} / \mathrm{mol}$ & $\mathrm{J} / \mathrm{mol} /$ degree & & $\mu M$ & $\mathrm{~kJ} / \mathrm{mol}$ & $\mathrm{J} / \mathrm{mol} /$ degree \\
\hline $\mathrm{wt}^{a}$ & $1.0 \pm 0.0$ & $21.1 \pm 10.2$ & $-54.3 \pm 0.7$ & $-41.4^{a}$ & $1.3 \pm 0.2$ & $7.5 \pm 3$ & $3.2 \pm 6.2$ & $0.7^{a}$ \\
\hline A66W & $1.3 \pm 0.1$ & $37.5 \pm 7.3$ & $-40.2 \pm 0.3$ & $2.8 \pm 1.1$ & & No det & le binding & \\
\hline Y53F/L57H & \multicolumn{4}{|c|}{ No detectable binding } & $1.3 \pm 0.0$ & $4.6 \pm 0$. & $.3 \pm 1.8$ & $28.4 \pm 5.6$ \\
\hline
\end{tabular}

${ }^{a}$ Parameters determined from the analysis of one data set. For experimental conditions see "Experimental Procedures."

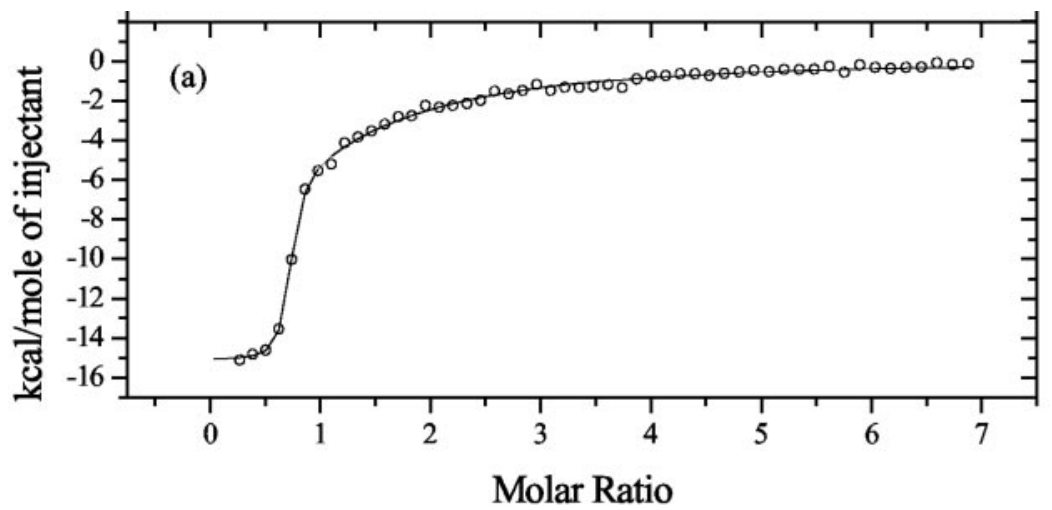

FIG. 7. Binding isotherms for the reactions between wt (a), $\mathrm{A66 \textrm {W }}(\mathrm{b})$, and Y53F/L57H $\mathrm{PpL}_{3316}$ and $\kappa_{1}$-light chain (c) in $20 \mathrm{~mm}$ potassium phosphate buffer, pH 8.0 at $15^{\circ} \mathrm{C}$. $a$, aliquots of 360 $\mu \mathrm{M} \kappa$-chain were titrated into $15 \mu \mathrm{M}$ wt $\mathrm{PpL}_{3316}$ corrected for the heat changes associated with the dilution of the $\kappa$-chain $b, 737 \mu \mathrm{M} \mathrm{A66W} \mathrm{PpL}_{3316}$ was titrated into $28.3 \mu \mathrm{M} \kappa_{1}$-chain. $c, 650 \mu \mathrm{M}$ Y53F/L57H $\mathrm{PpL}_{2316}$ were titrated into $25 \mu \mathrm{M} \kappa_{1}$-chain. Binding data from these titrations were analyzed using the manufacturer's software.
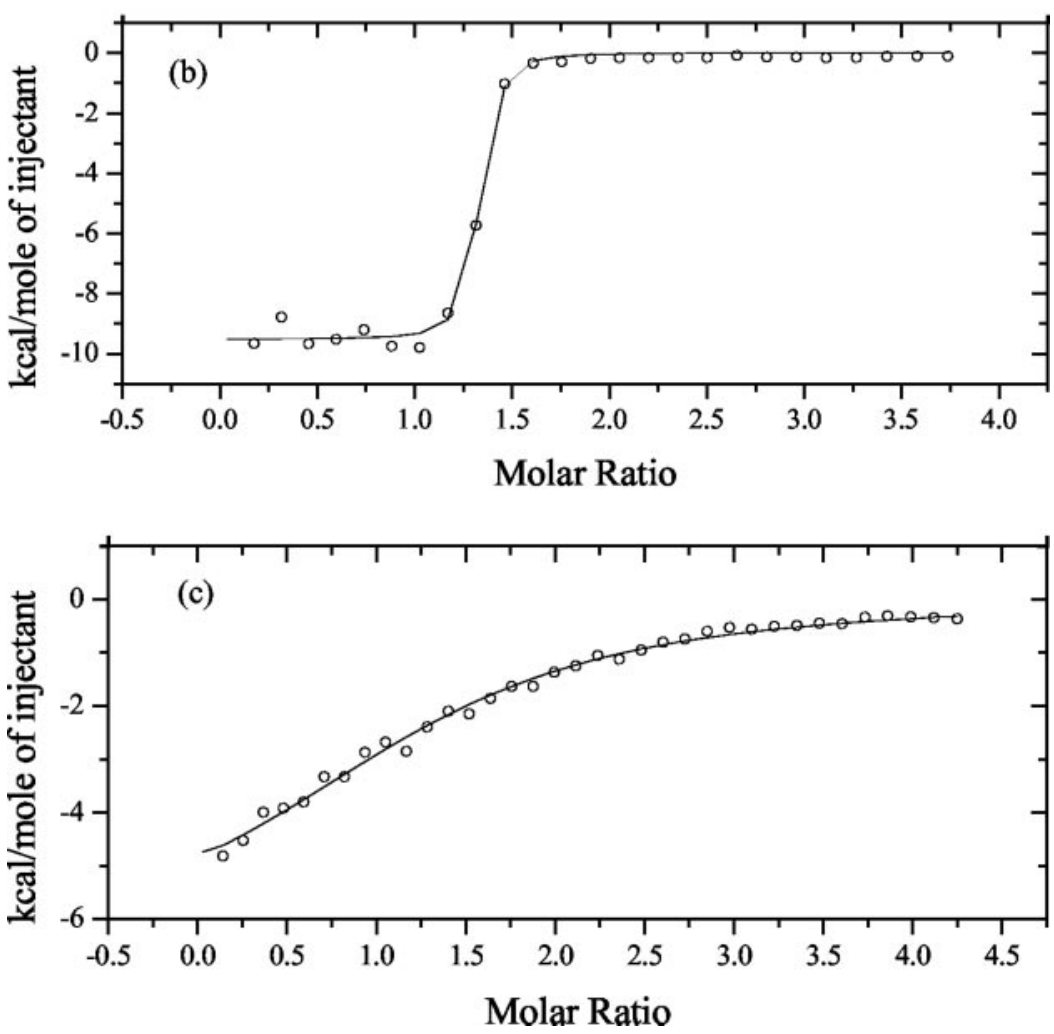

However, to accurately determine these values for each site, mutants in which either site 1 or site 2 had been eliminated were used. Titration of $\mathrm{Y} 64 \mathrm{~W} / \mathrm{Y} 53 \mathrm{~F} / \mathrm{L} 57 \mathrm{H} \mathrm{PpL} \mathrm{Pp}_{3316}$ into $\kappa$-chain allows the binding at site 2 to be measured. Clear enthalpy profiles are obtained (see Fig. 7), while titration of Y64W/Y53F/ L57H $\mathrm{PpL}_{3316}$ into buffer shows insignificant enthalpy changes. Analysis of the heat changes of the titrations fitted a one site binding model and indicated a $K_{d}$ value of $4.6 \pm 0.8 \mu \mathrm{M}$, an enthalpy change of $-21.3 \pm 1.2 \mathrm{~kJ} / \mathrm{mol}$ and an entropic change of $28.4 \pm 5.6 \mathrm{~J} / \mathrm{mol} /$ degree.

A66W $\mathrm{PpL}_{3316}$ was similarly used to study binding to site 1 in the absence of binding at site 2 . The A66W titration into $\kappa$-chain gives an enthalpy profile that fits a one site binding model with a $K_{d}$ equal to $37.5 \pm 7.3 \mathrm{nM}$, an enthalpy change of $-40.2 \pm 0.3 \mathrm{~kJ} / \mathrm{mol}$ and an entropic change of $2.8 \pm 1.1$ $\mathrm{J} / \mathrm{mol} /$ degree.

\section{CONCLUSIONS}

The experiments described above show conclusively that a $\mathrm{PpL}_{3316}$ domain has two binding sites for $\kappa$-chain of different affinities. The placement of unique Trp residues in either of the two binding sites has facilitated the binding constants to be determined and a model developed that explains the complex fluorescence signal changes noted previously. Estimates of $K_{d}$ 
by such techniques as enzyme-linked immunosorbent assay will reflect the presence of both sites. Thus we have resolved the issue by the production of mutants that have binding at one site or the other eliminated under these experimental conditions.

Fig. 2 shows that the final level of fluorescence $\left(\lambda_{\text {ex }}=295\right.$ $\mathrm{nm}$ ) from the complex formed by mixing a 1:1 mol:mol ratio of $\mathrm{Y} 64 \mathrm{~W} \mathrm{PpL}_{3316}$ and $\kappa$-chain is indicative of the relative occupancy of site 2 . Thus if all of the bound $\kappa$-chain is at site 1 , then there is little fluorescence increase at equilibrium from the $\operatorname{Trp}^{64}$ and vice versa. A domain with two sites of equal affinity would show equilibrium fluorescence intensity half way between the two extremes described above. We estimate that for

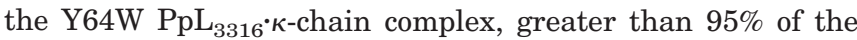
$\kappa$-chain is bound to site 1 , and this is reflected by an $\sim 2 \%$ net increase in the fluorescence intensity at equilibrium. The residual fluorescence intensity at equilibrium given by $\mathrm{Y} 64 \mathrm{~W} /$ $\mathrm{Y} 53 \mathrm{~F}$ is more than half of the fluorescence intensity difference given by $\mathrm{Y} 64 \mathrm{~W}$ and $\mathrm{Y} 64 \mathrm{~W} / \mathrm{Y} 53 \mathrm{~F} / \mathrm{L} 57 \mathrm{H}$ (which shows no binding at site 1). This therefore suggests that the Y64W/Y53F has an affinity for $\kappa$-chain at site 1 that is lower than its affinity at site 2 . This is supported by the $K_{d}$ values for the various complexes shown in Table III in which the $K_{d}$ for the I34W/Y53F

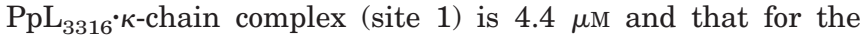
$\mathrm{Y} 64 \mathrm{~W} / \mathrm{Y} 53 \mathrm{~F} / \mathrm{L} 57 \mathrm{H} \mathrm{PpL} 3316^{\circ}{ }^{\kappa}$-chain (site 2) is $3.4 \mu \mathrm{M}$. In the $\mathrm{Y} 64 \mathrm{~W} / \mathrm{Y} 53 \mathrm{~F} / \mathrm{L} 57 \mathrm{H}$ complex $100 \%$ of the bound $\kappa$-chain is at site 2 , and hence this has a $K_{d}$ equal to $3.4 \pm 0.7 \mu \mathrm{M}$ (see Table III).

The new model that explains the biphasic fluorescence changes that occur on complex formation is consistent with previous data (9), although the previously proposed structural rearrangement (9), suggested by a slow change in fluorescence with a first order rate constant that is independent of the concentration of ligand, is now known to be the dissociation of $\kappa$-chain from the weaker site. Possible alternative models involving oligomeric forms of the protein can be eliminated as sedimentation studies carried out on $\mathrm{PpL}_{3316}$ have confirmed that the domain exists as a monomer in solution. ${ }^{2}$

The Y53F mutation dramatically increases the rate of dissociation of $\kappa$-chain from site 1 due to the loss of the hydrogen bond formed between the hydroxyl group and the peptide carbonyl group of $\mathrm{Thr}^{20}$. This leads to a decrease in affinity of at least 90 -fold to yield a $K_{d}$ of $4.42 \mu \mathrm{M}$, higher than in a previous report (9). However, it is now clear from the studies described in this paper that the affinity $(3.2 \mu \mathrm{M})$ measured in (9) was for $\kappa$-chain binding that was occurring at the then unreported weaker binding at site 2 .

To date, the binding of wt $\mathrm{PpL}_{3316}$ to two different $\kappa$-chains has been studied. These are a human $\kappa 1$-chain $\left(\kappa 1_{\mathrm{T}}\right)$ described

${ }^{2}$ B. J. Sutton and R. Beavil, personal communication. here and the other a human Fab (2A2 (10)). Additionally the binding of mutated $\mathrm{PpL}_{3316}$ domains to a murine $\kappa 9$ (Fab 19D9D6) has been studied (12). All of these confirm the presence of two binding sites per domain although the elimination of site 2 for the murine $\kappa 9$ (Fab 19D9D6) has been demonstrated for the mutant D55A (12). Binding at the second site is not easily detected due to the presence of the much higher affinity site 1 . However, this problem is eliminated when site 1 is either weakened or abrogated and thus by use of suitable mutants we have in these studies been able to measure the affinity of site 2 for $\kappa$-light chains.

Because the binding interactions at sites 1 and 2 involve backbone and different side chain contacts between $\mathrm{PpL}_{3316}$ and $\kappa$-chain, it is probable that the relative affinities of each site for $\kappa$-chains may depend upon the subclass or origin of the $\kappa$-chain. This may well offer an advantage to the bacterium, allowing it to maximize potential binding capacity.

Acknowledgments-We thank Prof. Martin Glennie, Tenovus Laboratories, Southampton, UK, for the kind gift of $\kappa 1_{\mathrm{T}}$-chain and Profs. M. T. Wilson and R. Eisenthal for helpful discussions.

\section{REFERENCES}

1. Kastern, W., Holst, E., Nielsen, E., Sjöbring, U., and Björck, L. (1990) Infect Immun. 58, 1217-1222

2. Åkerström, B., and Björck, L. (1989) J. Biol. Chem. 264, 19740-19746

3. Patella, V., Casolaro, V., Björck, L., and Marone, G. (1990) J. Immunol. 145, 3054-3061

4. Wikström, M., Drakenberg, T., Forsén, S., Sjöbring, U., and Björck, L. (1994) Biochemistry 33, 14011-14017

5. Wikström, M., Forsén, S., and Drakenberg, T. (1996) Eur. J. Biochem. 235, $543-548$

6. Wikström, M., Sjöbring, U., Drakenberg, T., Forsén, S., and Björck, L. (1995) J. Mol. Biol. 250, 128-133

7. Enokizono, J., Wikström, M., Sjöbring, U., Björck, L., Forsén, S., Arata, Y., Kato, Y., and Shimada, I. (1997) J. Mol. Biol. 270, 8-13

8. Bottomley, S. P., Beckingham, J. A., Murphy, J. P., Atkinson, M., Atkinson, T., Hinton, R. J., and Gore, M. G. (1995) Bioseparation 5, 359-367

9. Beckingham, J. A., Bottomley, S. P., Hinton, R., Sutton, B. J., and Gore, M. G. (1999) Biochem. J. 340, 193-199

10. Graille, M., Stura, E. A., Housden, N. G., Beckingham, J. A., Bottomley, S. P., Beale, D., Taussig, M. J., Sutton, B. J., Gore, M. G., and Charbonnier, J-B. (2001) Structure (Lond.) 9, 679-687

11. Beckingham, J. A., Housden, N. G., Muir, N. M., Bottomley, S. P., and Gore, M. G. (2001) Biochem. J. 353, 395-401

12. Graille, M., Harrison, S., Crump, M. P., Findlow, S. C., Housden, N. G., Muller, B. H., Battail-Poirot, N., Sibaî, G., Sutton, B. J., Jolivet-Reynaud, C., Gore, M. G., and Stura, E. A. (2002) J. Biol. Chem. 277, 47500-47506

13. Lakowicz, J. R. (1999) Principles of Fluorescence Spectroscopy, 2nd Ed., Kluwer Academic/ Plenum Press, New York

14. Gore, M. G., and Bottomley, S. P. (2000) Spectrophotometry and Spectrofluorimetry; A Practical Approach, 2nd Ed., Oxford University Press, Oxford

15. Kunkel, T. A., Roberts, J. D., and Zakour, R. A. (1987) Methods Enzymol. 154, 367-382

16. McPherson, S. G., and Mohler, (2000), PCR, BIOS Scientific Publishers, Oxford

17. Hiromi, K. (1979) Kinetics of Fast Enzyme Reactions, Halsted Press, New York

18. Stura, E. A., Graille, M., Housden, N. G., and Gore, M. G. (2002) Acta Crystallogr. Sect. D Biol. Crystallogr. 58, 1744-1748

19. Wilson, M. T., and Torres, J. (2000) Spectrophotometry and Spectrofluorimetry; A Practical Approach, 2nd Ed., Oxford University Press, Oxford 